\title{
VULNERABILIDADE SOCIAL ÀS MUDANÇAS CLIMÁTICAS EM CONTEXTOS RURAIS
}

\section{Heitor Marcos Kirsch}

Universidade do Estado de Mato Grosso (Unemat), Pontes e Lacerda - MT, Brasil. E-mail: heitor.kirsch@gmail.com

\section{Sergio Schneider}

Universidade Federal do Rio Grande do Sul (UFRGS), Porto Alegre - RS, Brasil. E-mail: schneider@ufrgs.br

DOI: http//dx.doi.org/10.17666/319106/2016

\section{Introdução}

A escala e intensidade das mudanças provocadas sobre o ambiente pela açáo humana a partir da Revolução Industrial atingiram níveis que causam uma crescente inquietaçáo sobre as condiçóes de sua irreversibilidade em termos globais (Biermann et al., 2012; Costanza et al., 2007). Alguns estudiosos sugerem que os efeitos mais severos desse movimento, sobretudo os climáticos, possivelmente ocorrerão nos países em desenvolvimento (Beg et al., 2002). Alertam igualmente que, em razão da significativa dependência das famílias em relação ao uso e manejo dos recursos naturais, o espaço rural é especialmente susceptível a tais impactos, embora se reconheça que os aglomerados urbanos localizados em zonas costeiras densamente povoadas, como na Ásia, também possam sofrer danos consideráveis (McGranahan et al., 2007).

Artigo recebido em 05/08/2014

Aprovado em 16/03/2016
A questão, como argumentam Mwang'ombe et al. (2011), é que, nas áreas rurais, estão concentradas as populaçóes com menor probabilidade para responder positivamente a essas mudanças. Portanto, uma proporção significativa desse contingente populacional está largamente susceptível ao solapamento dos mais diferentes meios que lhe garantem a sobrevivência. Além do mais, devido ao aumento da frequência e da intensidade dessas alteraçóes, estas poderão provocar reduçóes inesperadas e/ou frustraçóes nas colheitas agrícolas, o que também implicaria acentuada elevação dos níveis de desemprego, fato que, além de desestabilizar a segurança e a soberania alimentar, levaria a séria concorrência por recursos, os quais, então, se tornariam escassos. Portanto, é presumível que se exacerbem e radicalizem ainda mais as desigualdades e o bem-estar entre os países e entre os grupos sociais e indivíduos de uma mesma localidade.

Uma noção estreitamente vinculada a essa preocupação dos impactos da ação antrópica sobre o am- 
biente é a do risco que essas transformaçóes representam. Diferentemente do que ocorria nas sociedades pré-industriais, os meios de vida através dos quais indivíduos e sociedades contemporâneas viabilizam sua subsistência e reprodução podem, cada vez mais, ser afetados por eventos que extrapolam as fronteiras nacionais. As origens e abrangência desses "riscos modernos" acarretam os componentes da incerteza e da imprevisibilidade, o que compromete sensivelmente a forma como são percebidos e incorporados à dinâmica social. Desse modo, as ameaças que as mudanças do clima suscitam passam a ser fenômenos que não só afetam a sociabilidade como também implicam a construção social de representaçóes e dispositivos que são acionados de forma heterogênea $\mathrm{e}$ assimétrica (Beck, 2009).

No entanto, mais do que alertar sobre que a distribuição desigual dos efeitos catastróficos das mudanças climáticas, alguns pesquisadores demonstram preocupar-se com o fato de que esses riscos sistêmicos ainda não tenham conseguido produzir um senso de responsabilidade e compromisso social capaz de gerar mudanças comportamentais. Segundo especialistas como Lorenzoni et al. (2007), há um predomínio quase generalizado da percepção de que pouco pode ser alcançado através da mudança de hábitos e práticas rotineiras e cotidianas, o que remete a busca por soluçóes imaginadas - ou até mesmo a atribuição de culpas e de responsabilidades - ao campo da tecnocracia.

Diante de um quadro de condescendência, marcado por uma visão antropocêntrica com origens na filosofia iluminista, a natureza e o meio ambiente são interpretados de modo utilitarista e instrumental, como se fossem uma exterioridade ou algo a ser manipulado e ajeitado segundo o interesse e bem-estar dos humanos. Em outras palavras, há uma separação radical entre as esferas natural e social, dualismo que instrumentaliza e alicerça os princípios da racionalidade e os objetivos finais da modernização industrial com vistas à emancipação humana, como aponta, de maneira provocativa, Beck (2010). Por essas razóes, torna-se relevante e desafiadora a realização de análises sobre as implicaçóes e os modos de enfrentar os efeitos adversos que as mudanças climáticas poderão ocasionar, bem como suas possíveis relaçóes com os processos de desenvolvimento. Como apontado por Brown (2011), é preciso ir muito além da simplificada assertiva que associa, equivocadamente, o alívio da pobreza com a capacidade de gerar mecanismos de adaptação às mudanças climáticas.

Neste artigo, argumentamos que parte significativa das abordagens que tratam das consequências decorrentes da ação antrópica nos ciclos naturais continua restrita e presa às tradicionais avaliaçóes de caráter linear, prescritivo e normativo. O principal limite dessas abordagens é que não levam em consideração que a sociedade contemporânea está estruturada sobre bases que fazem uso ambientalmente insustentável e socialmente injusto dos recursos e dos ativos. Nesse sentido, procuraremos mostrar que esses limitantes advêm do fato de não refletirem ou sequer questionarem os processos de sobre-exploração dos serviços ecossistêmicos justamente porque se assentam em uma visão ontológica equivocada no que concerne ao entendimento da relação entre sociedade e natureza.

Da mesma forma, consideramos que é preciso ir além das maneiras ou abordagens que se autodefinem como alternativas para tratar dos desafios antes mencionados, e que argumentam a favor da necessidade de identificar e implementar soluçôes globais, com mecanismos de intervenção de caráter mais amplo para o tema. Ainda que se reconheça a importância e a relevância dessa postura epistemológica, propomos uma análise divergente, em que se privilegia uma perspectiva voltada ao entendimento das soluçóes locais, do modo como as populaçôes mais vulneráveis mobilizam certos meios de vida e os transformam em ativos para garantir sua subsistência.

Um avanço importante que a abordagem centrada nos meios de vida aportou refere-se ao papel determinante dos elementos naturais nas açóes preventivas ou reativas que buscam melhorar a resiliência e reduzir a vulnerabilidade ou ainda, melhorar a capacidade adaptativa dos grupos sociais (Ellis, 1998; Bebbington, 1999). Mas a principal contribuição dessa abordagem consiste em dimensionar as condiçóes objetivas de acesso aos ativos e seus determinantes causais em contextos locais (Scoones, 2009). Acreditamos que o domínio dessas condiçóes e a construção de capacidades adaptativas permitem desenvolver respostas adequadas aos contextos e situaçóes de vulnerabilidade. 
É certo que admitir essa posição traz implicaçóes às definiçóes das açóes políticas que visam estimular práticas sociais e econômicas mais sustentáveis, mas também traz efeitos contundentes sobre a noção de vulnerabilidade, a qual demanda tanto uma redefinição conceitual como um deslocamento de sua abrangência analítica. Basta lembrar que a noção vigente de vulnerabilidade trata das mudanças climáticas globais como um ruído ou alteração na relação entre os sistemas natural e humano, e é por isso que a definição de vulnerabilidade e suas consequências práticas centram-se primordialmente em aspectos relacionados como restabelecimento do equilíbrio de fluxos, quase sempre em termos estritamente biofísicos (Adger, 2006).

No Brasil, o debate entre especialistas e instituiçóes sobre o tema segue uma tendência de exames e propostas que privilegiam soluçóes setoriais, as quais, além de serem insuficientes, acabam por restringir o foco das avaliaçóes ao tratar dos efeitos e não das causas destes (Serrao-Neumann et al., 2013). Em razão disso, este artigo tem como objetivo contribuir não só com o debate para a superação de processos que privilegiam açóes de adaptação meramente instrumentais, como também para o deslocamento da atenção do entendimento analítico a respeito das maneiras de resistir ou se adaptar que os mais sensíveis às mudanças climáticas mobilizam, visando manter e melhorar seus meios de subsistência, por essas estratégias mobilizadas refletirem o funcionamento da arquitetura do quadro institucional. Em outras palavras, nossa intenção é demonstrar que são as condições objetivas do acesso à base de ativos locais e de sua capacidade de mobilização e/ou substituição os verdadeiros fatores causais da vulnerabilidade.

Para isso, iniciamos com o argumento de que isolar o clima enquanto variável determinante do comportamento e da qualidade das respostas dos agricultores denotaria o que Hulme (2011) classificou como "reducionismo ambiental". Tomadas de decisóes independem da precisão dos modelos que estimam o comportamento do estado futuro do clima, visto que elas são feitas não somente considerando-se este, mas também fatores de ordem econômica, política e cultural. Depois analisamos os efeitos da ambiguidade que permeia a noção de vulnerabilidade, argumentando que uma resposta adaptativa robusta somente é atingida quando se incorporam perspectivas que não ignoram os fatores que condicionam a construção ou a erosão dos elementos socioecológicos que integram a resiliência dos sistemas.

Procuramos sublinhar a importância de incluir na discussão do quadro teórico-analítico a forma e a disposição dos arranjos institucionais e dos contextos políticos e culturais. O principal motivo para tanto é que a sustentabilidade e as respostas eficazes frente às mudanças climáticas, sobretudo aquelas produzidas pelas famílias que residem em espaços rurais, estão diretamente relacionadas com a facilidade com que um ativo pode ser permutado ou modificado. Por fim, pontuamos que uma mudança no enfoque das ações que objetivem a construção de capacidades adaptativas e de enfrentamento requer a identificação das cadeias causais da vulnerabilidade social em vez de priorizar açóes infraestruturais e de planejamento e gerenciamento científico-burocrático das respostas atuais e futuras às mudanças climáticas.

\section{Mudança climática: reconhecendo as incertezas na produçáo de respostas}

Evidências científicas cada vez mais robustas e consistentes apontam que a insustentabilidade que se verifica nos sistemas ambientais é causada pelos efeitos da atividade humana (Gleckler et al., 2012; Rockström et al., 2009). Morand et al. (2012) demonstraram que, mesmo populaçóes tradicionais, como a dos pescadores do Delta do Níger, no Mali, tornaram-se altamente sensíveis às recentes variaçôes e mudanças nos ciclos hidroclimáticos. Suas estratégias de subsistência, embora diversificadas e bem adaptadas às condiçóes locais ao longo da sua história, já não conseguem responder adequadamente aos problemas e restriçóes ambientais.

Entretanto, tais evidências ainda comportam grande incerteza acerca das estimativas de comportamento dos ciclos naturais, o que oferece limites às projeçóes temporais futuras. Um dos motivos apontados para essas restriçóes refere-se à incapacidade em se estabelecerem prognósticos unidimensionais de determinísticos (Schneider, 2002a). Em parte, 
esses obstáculos estấo associados à própria variabilidade natural, que envolve a substituiçáo generalizada dos recursos ambientais em ciclos geofísicos, gerados tanto por forças internas e/ou externas aos sistemas naturais, quanto por mudanças cíclicas na atividade solar e erupçōes vulcânicas. Portanto, esses fatores contribuem, ainda que náo decisivamente, para a incerteza nas projeçóes nos modelos climatológicos. Conduzem a uma postura em que a análise do comportamento futuro dos efeitos da mudança climática não pode ser considerada além de uma probabilidade (Stott e Kettleborough, 2002).

Um exemplo nesse sentido está relacionado com a verificação de que o aquecimento global estaria ocorrendo de modo mais intermitente e menos previsível do que algumas simulações presumiam. Apesar do contínuo aumento das concentraçôes atmosféricas de gases de efeito estufa, a temperatura global anual média apresentou uma espécie de "hiato" desde 1988, quando houve registros recordes, não existindo alteração significativa desde entâo (Kosaka e Xie, 2013).

Vale notar que o cenário provável apontado pelo último relatório do Intergovernmental $\mathrm{Pa}$ nel on Climate Change (IPCC) (Alexander $e t a l$., 2013) alerta para um aumento projetado na temperatura média da superfície global entre $0,3^{\circ} \mathrm{C} \mathrm{e}$ $4,8^{\circ} \mathrm{C}$ até o final do presente século, utilizando-se como referência as observaçóes do período de 1986 a 2005. A confirmar-se esse prognóstico, o derretimento de geleiras na Groenlândia e em partes da Antártida deverá se acelerar e alcançar uma faixa entre 26 a 82 centímetros até 2100 . Também são esperadas temperaturas extremas, tanto de frio quanto de calor, em maior frequência sobre a maioria das áreas de terra em escalas de tempo diárias e sazonais, e é muito provável que ondas de calor irão ocorrer com maior frequência e duraçáo em alguns locais, enquanto ocasionais frios extremos no inverno continuarão a ocorrer em outros. $\mathrm{O}$ referido relatório também alerta para o aumento da acidificaçáo dos oceanos, uma ameaça evidente para a biodiversidade marinha, para interrupçôes do ciclo global da água e disponibilidade de água doce em um número crescente de localidades devido a mudanças nos padróes de precipitação (Alexander et al., 2013).
No Brasil, o Painel de Mudanças Climáticas projeta que, ao final deste século, poderá haver uma diminuiçãoo de $40 \%$ a $50 \%$ da distribuição das chuvas no bioma Caatinga, o que deverá agravar sensivelmente a disponibilidade hídrica desse local (Ambrizzi et al., 2013). Se confirmado esse cenário, a disponibilidade de água no Semiárido deverá ser ainda mais crítica, visto que a demanda atual já é superior aos seus mananciais em 1.133 de seus municípios que abrigam 20 milhōes de pessoas, $44 \%$ das quais residentes em espaços rurais (ANA, 2010).

Como lembram Adger et al. (2009), o clima é apenas um de muitos processos que cotidianamente influenciam as sociedades e os indivíduos em suas atividades, muitos deles igualmente incertos. Assim, as abordagens sobre projeções dos efeitos das mudanças climáticas em seus aspectos técnicos e científicos aparecem intrinsicamente conectadas com questôes que abarcam as dimensōes sociais e humanas, e o entendimento mais abrangente desse fenômeno congrega tipos de incerteza que são complexos para serem mensurados, quantificados e/ou estimados, o que extrapola as fronteiras dos paradigmas da ciência objetiva (Reilly et al., 2001; Schneider, 2002a). Uma das razōes reside no fato de que há divergências na própria percepção dos indivíduos sobre a seriedade náo somente dos riscos e perigos, como também dos possíveis efeitos das mudanças climáticas.

Vale notar que, para Beck (2009), a noçáo de risco somente existe em um estado permanente de virtualidade, uma antecipação dos efeitos catastróficos futuros, no presente. Ou seja, não há critérios objetivos para determinar que eles "sejam reais". Eles "se tornam reais" por meio de um processo de presentificação. Sua materizalização enquanto existência fictícia é um exercício político e elemento essencial na orientação das expectativas e/ou na definição das estratégias de ação. Suas avaliações e julgamentos estão impregnados de subjetividade, dando-se pela percepção, o que lhes confere a falta de concretude espaço-temporal. Dito de outro modo, o sentido social que é conferido às mudanças climáticas e seus efeitos correspondem a coisas e valores muito distintos para os diferentes indivíduos e/ou grupos sociais (Dessai et al., 2009).

O que pretendemos sublinhar é que os esforços para produzir respostas adequadas tendo como 
ferramenta principal modelos de previsóes climatológicas são insuficientes, ainda que se reconheça sua importância. A relação desse processo vai muito além de sua circunscrição como problema de ordem física. Mais do que medidas tecnológicas ou soluçôes infraestruturais de engenharia, geralmente onerosas em termos ambientais, é preciso construir estratégias e/ou capacidades adaptativas que inevitavelmente partam dos próprios meios de vida das populaçôes, pois somente essa característica permite que tais medidas sejam percebidas, reconhecidas e adotadas como válidas. É precisamente esse aspecto que lhe confere robusteza.

Açóes adaptativas sistematicamente remetem para a necessidade de uma análise das estratégias desenvolvidas e institucionalizadas por uma memória social compartilhada. Elas são, muitas vezes, baseadas na experiência cotidiana e, por analogia, podem variar consideravelmente entre indivíduos e grupos sociais. Mamun (2010) demonstra como os sistemas de conhecimento e práticas desenvolvidas ao longo do tempo sáo ainda hoje ferramentas importantes e valiosas para os processos de compreensão dos ecossistemas, bem como para promover respostas em nível local com a intenção de evitar os efeitos negativos das mudanças ambientais entre os pescadores no Bangladesh.

Como se pode perceber, as decisóes são tomadas a partir de uma ampla e variada gama de cenários presumíveis, não somente sobre o estado futuro do clima, mas também sobre muitos outros fatores econômicos, políticos e culturais (Adger et al., 2009). As estratégias que pretendam ser robustas e sustentáveis são, inevitavelmente, indiferentes à necessidade de debelar as incertezas (Dessai et al., 2009). Somente a partir desse horizonte é possível determinar como as mudanças climáticas podem afetar o que é importante, e, dessa maneira, capturar a direção de tendência dos fatores que condicionam e modelam a sua vulnerabilidade.

\section{Delimitando a noçáo de vulnerabilidade}

Diante do complexo acoplamento que se estabelece entre os sistemas humanos e naturais para a compreensão da sustentabilidade, a noção de vul- nerabilidade é um elemento importante para a avaliação e compreensão dos processos sociais e econômicos (Turner II et al., 2003), primordialmente, porque sua caracterização e enquadramento teórico remetem a discursos diferentes sobre o tema, o que resultou na produçáo de tipos de conhecimentos acadêmicos e tipologias de respostas que invariavelmente nortearam, em longa data, as açōes de intervenção política (O’Brien et al., 2007).

Kirkby et al. (2001) destacam que, desde a década de 1970, há uma crescente polarização em dois grandes campos nessas abordagens, sobretudo em termos de abrangência dos fatores causais e de suas implicaçôes práticas. As primeiras perspectivas, qualificadas como comportamentais, tiveram sua origem ligada às ciências naturais, particularmente à biologia evolutiva, e se concentraram nos estudos dos fenômenos geodinâmicos, hidrometeorológicos e tecnológicos (Smit e Wandel, 2006). Nestas, a vulnerabilidade é compreendida como o resultado final ou fruto do exame "que começa com projeçôes de tendências de emissóes futuras, avançando para o desenvolvimento de cenários climáticos, daí para os estudos dos impactos biofísicos e na identificaçáo das opçôes de adaptação" (Kelly e Adger, 2000, p. 327). Segundo Adger (2006), a vulnerabilidade é interpretada como resultado, em termos negativos, da susceptibilidade e incapacidade de um sistema natural/social de lidar com os efeitos adversos resultantes das mudanças climáticas no momento em que estes o assolam.

Limitar o entendimento sobre vulnerabilidade com um foco restrito à identificação das perturbaçôes e aos estressores é insuficiente para compreender os impactos e as respostas diferenciais dos sistemas ou de seus componentes, argumentam Turner II et al. (2003). O motivo é que essa forma de entendimento não considera a sequência causal da situação do perigo, o que dificulta sua análise em termos relacionais.

Kelly e Adger (2000) entendem que, para caracterizar a vulnerabilidade, é preciso compreender e avaliar adequadamente os processos sociais e econômicos, e que, por isso mesmo, a condição de vulnerabilidade representa "o ponto de partida" da análise dos impactos. As adaptaçôes não são destinadas a evitar diretamente os impactos, mas a re- 
duzi-los quanto aos perigos, conduzindo para uma atenção às ações e aos fatores condicionantes dos ajustes no âmbito da comunidade e das famílias. Portanto, esse enfoque privilegia um exame sobre as causas estruturais dos riscos e perigos enquanto fatores determinantes da vulnerabilidade na medi$\mathrm{da}$ em que a forma e o modo de acesso aos direitos institucionalmente garantidos das pessoas, ou seja, seus intitulamentos, tal como definido por Sen (2001), podem facilitar ou dificultar as respostas às mudanças sociais e ecológicas. Sob essa ótica, há uma relativização na compreensão de perigos físicos e desastres ambientais enquanto fatores determinantes que levam a população às situaçóes de vulnerabilidade. $\mathrm{O}$ entendimento e a percepção desta são necessariamente situacionais e contextuais, essencialmente um estado variável e relacional de uma posição de um indivíduo/grupo em comparação com outro, que não se encontra em situação de vulnerabilidade.

Essa assimetria de situaçóes é determinada pela ligação entre os ativos e as opções de oportunidades que essas pessoas possuem na prática para responder a uma situação de risco ou perigo (Ellis, 2000). Beck (2009) afirma que é justamente essa desigualdade que permite que os riscos sejam minimizados por uns por uns e maximizados por outros, o que revela a existência de profundas raízes sociais e implicaçóes éticas, políticas e morais. Em outras palavras, está associado à noção seniana da capacitação (capability) (Sen, 2001).

Segundo Adger (2000), a análise da estrutura institucional é um componente central na ligação estabelecida entre a resiliência social e ecológica na medida em que as oportunidades e perspectivas estão decisivamente relacionadas com a variedade de instituiçôes existentes e do modo como funcionam. Portanto, os fatores que são determinantes para a capacidade de enfrentamento ou adaptação não podem ser tomados de maneira independente uns dos outros (Smit e Wandel, 2006). Isso se caracteriza como um processo interativo de aprendizagem social entre os indivíduos e as instituições e seu ambiente biofísico (Adger e Kelly, 1999).

Em um contexto de mudança climática, a adaptação é um processo de ação reflexiva, resultado de uma aprendizagem individual e/ou coletiva, sobretudo dos períodos de turbulência de eventos extre- mos, mediada pelo conjunto de instituiçóes e pelas relaçôes sociais que atuam em diferentes níveis numa localidade, situados em um contexto específico de paisagem. Mais importante do que a construção de qualquer medida mensurável, o essencial é a captura da trajetória de tendência dos fatores que condicionam e modelam a vulnerabilidade. Esta é, segundo Adger e Kelly (1999), a base que permite a análise do estado de resiliência social e/ou vulnerabilidade aos processos de mudanças climáticas.

Consequentemente, há uma explícita divergência sobre a centralidade do fator determinante. Enquanto a primeira abordagem centra atenção nos elementos externos dos desastres associados aos perigos naturais, a segunda privilegia o elemento interno, ou seja, os fatores que condicionam a capacidade de resistir aos riscos ou se adaptar aos desastres e uma mudança generalizada do ambiente. Esta última posição sugere uma conexão conceitual entre vulnerabilidade e resiliência e a arquitetura dos intitulamentos, em que o desenho institucional e organizacional medeia a capacidade das famílias em buscar e conceber estratégias de subsistência para lidar com os perigos ou choques (Ellis, 2000). Assim sendo, o entendimento da conjuntura dos riscos a qual os meios necessários para a subsistência da vida das famílias rurais estão submetidos é primordial para a análise das tendências de vulnerabilidade, cujo quadro analítico é capturado pela abordagem dos meios de vida, que, dada a imprecisão da tradução para a língua portuguesa, faz referência à sustainable livelihoods approach, detalhada a seguir.

\section{A abordagem dos meios de vida: uma resposta ao entendimento da vulnerabilidade no meio rural}

Muitas vezes, os meios de subsistência das famílias rurais estão sujeitos e são confrontados com situaçóes de choque e tensóes que podem aumentar sua vulnerabilidade. Diante de tais condiçôes, não raro, a possibilidade que lhes resta é seguir em direção às áreas urbanas, onde suas habilidades rurais quase sempre são difíceis de serem implantadas e implementadas. 
Por essa razão, deter-se em analisar as possíveis alteraçóes dos regimes climáticos e o aumento na frequência de eventos extremos apontadas por diversos estudos, que deverão resultar em uma série de efeitos diretos e indiretos sobre a atividade agrícola, sobretudo daqueles dependentes do uso e do manejo dos recursos naturais, se torna uma exigência premente (Alexander et al., 2013; Ambrizzi et al., 2013). Como, já a partir da segunda metade do século XXI, são esperadas variaçóes de rendimento quanto a quantidade e qualidade em diversos tipos de cultivos em regióes, como no continente africano e asiático, e ainda há a probabilidade de reduçóes de taxas próximas aos $16 \%$ para o milho e $11 \%$, para sorgo no Sul da Ásia, enquanto, na África, a produção de trigo deverá diminuir em $17 \%$; o milho, em 5\%; o sorgo, em 15\% e o milheto, em 10\% (Vermeulen et al., 2012), a abordagem dos meios de vida pode fornecer uma linha de base promissora para investigar como ocorrem os processos de adaptação ou de enfrentamento aos riscos diante de tais condiçóes no contexto rural.

Essa sinalização é importante porque se estima que, em 2013, houve um número próximo a 842 milhóes de pessoas no mundo incapazes de satisfazer as suas necessidades de energia em sua dieta diária. Ou seja, $12 \%$ da população global provavelmente está sofrendo de fome crônica, náo conseguindo disponibilizar alimento suficiente para uma vida ativa e saudável, como alerta o relatório da FAO, IFAD e WFP (2013). Este ainda aponta que a absoluta maioria, quase 827 milhóes, vive em regióes consideradas em desenvolvimento. Somente as regiôes da Ásia e da África Subsaariana concentram uma taxa pouco inferior a $90 \%$ desse total.

Alguns ensaios ao longo de séries temporais no continente africano também apontaram a importância da água e do calor no cultivo de alguns cereais. $\mathrm{Na}$ produção do milho de sequeiro, a cada dia em que se registraram temperaturas acima de $30^{\circ} \mathrm{C}$ houve redução média de $1 \%$ no rendimento final e de até $1,7 \%$ sob condiçôes de seca (Lobell et al., 2011). Outros pesquisadores, como Vörösmarty et al. (2010), sublinham que o recurso hídrico não é somente importante para a produção de alimentos, mas também para a segurança humana. Segundo eles, nos dias atuais, a taxa da população mundial que já enfrenta algum tipo de desafio em relação ao acesso à água para satisfazer suas necessidades básicas está próxima dos $80 \%$, e 1,7 bilhão de pessoas no mundo enfrentam uma situação de escassez altamente crônica desse recurso.

Gupta (2013) sugere que essa restrição está associada, entre outras razóes, a formas inadequadas de consumo e à má gestão do uso da terra, que inclui os processos de desmatamento e um conjunto de práticas agrícolas caracteristicamente não sustentáveis. Em decorrência desses fatores, segundo Bai et al. (2008), 24\% de toda área de terra do globo apresenta algum tipo de degradação, o que afeta o meio de vida de aproximadamente 1,5 bilháo de pessoas.

No Brasil, alguns estudos têm enfatizado que, por conta das mudanças climáticas, é bastante presumível que, em poucas décadas, deverá haver deslocamentos de vários cultivos, de localidades que atualmente são climaticamente favoráveis, para outras onde não se observa sua ocorrência (Embrapa e Unicamp, 2008; Marengo, 2007). Isso significa que, assim como em várias outras partes do globo, provavelmente ocorrerá uma grande modificação do atual zoneamento agrícola no país, o que poderá acentuar as atuais desigualdades regionais (Moraes et al., 2011; Thornton, 2012).

Uma das questóes preocupantes relacionadas com esses cenários prováveis de transformação nos ciclos naturais, combinados com fatores de ordem social, é que, em algumas localidades, podem resultar em situações de fome e escassez de alimentos, como assinalam Beddington et al. (2012). A necessidade de introdução de novos alimentos para satisfazer necessidades nutricionais da população, particularmente aqueles ligados aos cultivos de trigo, arroz e milho, que fornecem mais da metade das calorias consumidas globalmente, e os alimentos que são fontes de proteínas de origem animal e vegetal, parece ser uma realidade cada vez mais próxima (Thornton, 2012).

Essas constataçôes reforçam a ênfase dispensada em vários estudos a respeito do impacto negativo que o atual sistema produtivo agrícola exerce sobre alguns dos principais serviços ecossistêmicos, o que é asseverado pelas mudanças nos regimes climáticos (Ricketts et al., 2004; Smith et al., 2008). No entanto, é importante ressaltar que o movimento 
das últimas duas décadas do século XX, ligado ao meio ambiente e ao desenvolvimento, concentrou-se em vincular a necessidade de alívio da pobreza como condição para a sustentabilidade, tornando-a um grande léxico, sobretudo a partir da publicação do Relatório Brundtland (CMMAD/ONU, 1991).

Segundo Wisner et al. (2004), se a pobreza de fato causa impacto na vulnerabilidade das pessoas e na sustentabilidade do desenvolvimento, é importante reconhecer que ela não deriva somente da localização física. Há causas e condiçôes políticas e econômicas subjacentes e que normalmente são longínquas em termos temporais (Viola, 2002). Com isso, muitas vezes omite-se o aspecto de que uma mudança nos padróes climáticos que desestabilize os atuais sistemas agrícolas possivelmente trará ainda mais dificuldades para milhōes de pessoas em alcançarem a segurança alimentar $\mathrm{e}$ nutricional, que já é problemática em várias partes do mundo. Para Vermeulen et al. (2012), relega-se uma atenção muitas vezes secundária à questão dos efeitos e consequências da volatilidade dos preços dos alimentos sobre as pessoas em situação de pobreza e insegurança alimentar em consequência dos aumentos dos eventos climáticos extremos, como secas e inundaçóes e mesmo de ondas de calor.

Todavia, as comunidades, e mesmo os agregados familiares, não são homogêneos. Sua vulnerabilidade tende a variar em virtude da disponibilidade e do acesso diferencial de características como estatutos socioeconômicos, gênero, idade, etnia, filiação política e religiosa (Few, 2003). Segundo dados do estudo realizado pela UNCCD (2011) em comunidades rurais em Uganda, na África, o acesso das mulheres aos ativos é fortemente mediada pelas relaçôes de gênero. Este estudo revela que, apesar de $97 \%$ das mulheres terem acesso à terra, apenas $7 \%$ delas têm direito a propriedade desta e que o mesmo percentual dessas mulheres, segundo o que estas revelaram, desfruta de acesso ao crédito. Outro aspecto também ressaltado pelo documento é que estas, especialmente as mais pobres, possuem uma substancial limitação no acesso à informação e educação em relação aos homens, o que, muitas vezes, resulta na falta de estratégias organizacionais e de processos de gestão ambiental adequados. Portanto, as famílias chefiadas por mulheres nesses locais estão em maior desvantagem do que as que são chefiadas por homens, o que as torna mais vulneráveis aos efeitos das crises ambientais e econômicas.

Outra questão importante que ainda está associada a essa situação é que, segundo dados da Unesco (2010), dentre cada três adultos analfabetos no mundo, dois são do sexo feminino. Uma pesquisa realizada por Mendonça e Motta (2007) revelou que a redução do analfabetismo das mães com idade superior a 15 anos é a maneira mais barata e abrangente de combater a mortalidade infantil no Brasil, conseguindo-se salvar uma vida com o investimento de $\mathrm{R} \$ 63$ mil, enquanto seriam necessários $\mathrm{R} \$ 241$ mil e $\mathrm{R} \$ 168$ mil em coleta de esgoto e tratamento de água, respectivamente, para o mesmo resultado.

De modo semelhante, Lindoso et al. (2005) sugerem que, com base em um estudo realizado em sete municípios do sertão, no estado do Ceará, a propriedade da terra e habilidades individuais como ler e escrever são aspectos fundamentais para o acesso às informaçōes, às linhas de crédito disponibilizadas pelas políticas públicas e para o exercício da cidadania. Nessa localidade, apenas 34\% dos agricultores familiares eram proprietários da terra e $57 \%$ destes informaram ter o domínio da escrita e da leitura. Outra observação importante salientada pela pesquisa é a baixa participaçáo destes em associaçóes ou entidades de classe. Essa característica foi identificada em apenas $2 \%$ dos estabelecimentos. Lindoso et al. (2005) avaliam que tal especificidade expôe os agricultores a situaçôes que incrementam a vulnerabilidade, visto que organizaçōes dessa natureza são espaços de aprendizagem coletiva e refletem a presença de redes sociais, apontados como extremamente importantes na manutenção ou restauraçáo da sustentabilidade.

Dentro da abordagem dos meios de vida, a noção de sustentabilidade faz referência direta ao modo de lidar com os choques e tensóes, como forma de reduzir a situação de vulnerabilidade. Morton (2007), por exemplo, identificou que os pastores no Norte do Quênia e Sul da Etiópia utilizam os rebanhos de várias espécies como uma forma de poupança para enfrentar períodos de escassez, o que, além disso, lhes proporciona uma considerável vantagem em termos de mobilidade se tal atividade for comparada a outras de cunho agrícola em 
períodos de seca prolongada. Isso significa que o desenho do modo e da maneira como os indivíduos ou famílias conseguem exercer suas capacitaçóes e escolhas - ou, em sentido oposto, são inibidos de fazê-lo - estão diretamente conectados e mediados pela arquitetura das relaçóes sociais, das instituiçóes e organizaçóes presentes e pela maneira como operam em diferentes níveis de escala e tempo.

Ellis (2000) observa que a característica dos critérios que definem o acesso e uso dos ativos é predominantemente vinculada aos fatos sociais de ordem endógena ao agregado familiar. No entanto, é importante frisar que não se ignora que a definição da estratégia a ser adotada para viabilizar o meio de vida da família também é dependente de fatores que lhes são exógenos e, dessa maneira, inserida em contextos mais amplos. Implica, igualmente, que não estão imunes aos efeitos das tendências econômicas e/ou políticas e choques imprevistos, tais como eventos extremos ou uma mudança climática, que podem, sob certas circunstâncias, provocar desdobramentos que não são controláveis pelo agregado familiar. Por conseguinte, a vulnerabilidade de um meio de vida está diretamente relacionada com as capacidades ( $c a-$ pabilities) de substituição de ativos e/ou atividades do agregado familiar e de produzir respostas robustas que se reportem às estratégias de enfrentamento ou adaptação (Ellis, 2000).

Logo, uma análise que incorpore essa abordagem necessariamente deve retratar a complexa teia de atividades e interaçóes que enfatizam a diversidade de atividades quanto ao modo como as pessoas vivem, servindo-se, para tanto, de uma complexa forma de combinaçôes de ativos e atividades. Por essa razão, a maneira como as combinaçóes variam e como essas diferentes estratégias afetam as trajetórias deve ser preocupação importante para a análise dos meios de vida (Scoones, 2009, 2015). Significa levar em consideração os recursos que estão disponíveis para proporcionar a capacidade das famílias de construírem uma situação julgada como satisfatória pelos próprios, os fatores de risco na gestão de seus recursos, bem como o contexto político e os arranjos institucionais, que, de alguma forma, podem colaborar na busca de uma alternativa viável de melhorar sua condição de vida ou que podem, até mesmo, limitá-la.
Alguns estudos, por exemplo, têm chamado a atenção ao fato de que os processos de erosão e desgaste de solos e de mudanças nos ciclos climáticos e nos eventos extremos, ou, quando associados, favorecem processos de migração de áreas rurais para urbanas e a disseminação de doenças infecciosas endêmicas (Assad et al., 2013; Hogan, 2005). Oscilaçôes climáticas apontadas como o principal motivador da seca no estado do Maranhão entre 1982 e 1983 levaram um grande contingente de trabalhadores rurais a migrar para o estado do Pará. Estes, ao retornarem aos locais de origem, espalharam focos de malária, doença adquirida naquele estado, conforme informaçóes do Centro de Desenvolvimento e Planejamento da Faculdade de Ciências Econômicas da UFMG e a Fundação Oswaldo Cruz (Cedeplar-UFMG e Fiocruz, 2009). Franke et al. (2002) estabeleceram uma relação direta entre o El Niño, nas décadas de 1980 e 1990, e a ocorrência de doenças como a leishmaniose visceral. Eles verificam que houve aumento na variação da incidência anual em cerca de 50\% na Bahia, pouco tempo após a ocorrência do fenômeno climático, em vários momentos.

Portanto, quanto mais fácil um ativo puder ser construído, adquirido, convertido em outro ou modificado em sua composição, maior será a sustentabilidade e, consequentemente, a possibilidade de sucesso em respostas de enfrentamento e/ou adaptação dos meios de vida às situaçôes provocadas pelas mudanças climáticas (Ellis, 2000). No entanto, construir essa capacidade adaptativa nem sempre é um procedimento fácil e simples, pois traz implicaçóes bastante profundas no que diz respeito à determinação de prioridades em torno das políticas públicas.

\section{Consideraçóes finais}

Neste artigo, procuramos demonstrar que o conjunto de respostas apresentadas à crise socioambiental moderna que subverte a noção de ambiente a uma categoria utilitarista são frágeis e apresentam claras limitaçóes por serem marcadas por uma lógica reducionista, linear e fragmentadora. Por esta razão, argumentamos, não há avanço na discussão a respeito do que é, de fato, o cerne da questão: a 
finitude dos recursos naturais e os limites dos sistemas biofísicos planetários. Em outras palavras, esse conjunto de respostas limita o entendimento da noção de natureza a um recurso a ser utilizado para o bem-estar material do homem.

É possível alegar que esse olhar é o reflexo de um modelo de sociedade cuja estrutura de funcionamento expóe, de modo crescente, uma dinâmica insustentável em termos ambientais e socialmente marcada pela injustiça. Ao mesmo tempo, remete a propostas de adaptaçóes a esses novos cenários que não instigam um questionamento mais contundente ao estilo de desenvolvimento globalizado e estandardizado, manifestado principalmente nos processos de modernização da agricultura, da contínua urbanização e de uma sobre-exploração dos serviços ecossistêmicos.

Os desafios que surgem em face de uma mudança nos ciclos climáticos para os estudos rurais envolvem, em particular, esforços que não podem ficar restritos à identificação de estratégias de adaptação no setor agrícola. Eles precisam levar em consideração que as principais metas das estratégias de adaptação, que buscam não só reduzir a vulnerabilidade às mudanças climáticas, como também manter e melhorar os meios de subsistência das populaçóes, devem ser contextualizadas em uma compreensão de como os mais pobres e vulneráveis mobilizam seus meios de subsistência.

Adicionalmente, persistem lacunas importantes na identificação do papel dos recursos naturais na realização dos meios de vida dessas populações e também das possibilidades de ações de adaptação que reduzam as vulnerabilidades e aumentem a resiliência dessas pessoas. Não basta a adoção de variedades específicas de cultivos para lidar com as condiçóes locais e/ou a diversificação de produção agrícola para reduzir a vulnerabilidade das pessoas. Para um contingente significativo das populações que vivem em áreas rurais e em situação de pobreza nos países em desenvolvimento, o modo de resistir ou adaptar-se está primordialmente assentado nas condiçóes objetivas do acesso à base de ativos locais e de sua capacidade de substituição. Em outras palavras, centrar exclusivamente a atenção na adaptação instrumental às alterações climáticas é um reducionismo da temática que desvia a atenção de outros fatores causais que muitas vezes desempenham um papel mais importante na manutenção da vida no espaço rural.

Neste artigo, argumentamos que problematizar e discutir as formas e o conteúdo de respostas que sejam robustas e eficientes às mudanças climáticas, inevitavelmente, deve estar vinculado à noção de vulnerabilidade que permeia a condição de vida das populaçóes afetadas. Compreender adequadamente seu sentido assume um caráter central, uma vez que pode determinar o tipo, a forma e as prioridades que as políticas públicas irão enfocar. Açóes de intervenção que se concentram na implementação tecnocrática de medidas preventivas tendem a produzir resultados menos eficazes, ou mesmo contraproducentes, visto que obscurecem a identificaçâo das condiçóes que podem incorrer em uma situação que fragiliza a resiliência e/ou a capacidade adaptativa dessas pessoas. É preciso, portanto, prestar mais atenção aos determinantes causais da vulnerabilidade social do que aos seus sintomas.

Isso torna pertinente a análises da vulnerabilidade que privilegiem os arranjos em nível local e, mais especificamente, as dinâmicas que definem e medeiam as estratégias de atividades dos agregados familiares no espaço rural, tal como proposto pela abordagem dos meios de vida. Mas, esse enfoque também deriva em implicações políticas que são relevantes de serem destacadas. Uma delas é reconhecer a coevolução entre os ecossistemas e as sociedades humanas, passando-se a considerar que a forma como as sociedades evoluíram é fruto da sua relação com o uso dos recursos naturais. Ignorar ou limitar a dinâmica que resulta dessa dupla relação é um imenso equívoco.

Um segundo aspecto que precisa ser considerado é que esse processo pode gerar açóes reflexivas dos indivíduos para enfrentar situaçóes novas e não previstas, adaptando-se segundo suas necessidades e interesses. Um corolário que deriva deste entendimento é que as estratégias e as opçóes preferenciais das populaçôes podem não necessariamente coincidir com as recomendaçóes dos policy makers.

Argumentamos que considerar a vulnerabilidade simplesmente como o resultado da exposição às perturbaçôes dos fatores naturais é simplificar demasiadamente a temática que envolve o processo de 
adaptação às mudanças climáticas globais. Atribuir-lhe uma característica social, contextual e variável, ponderando a complexa teia de conexóes e interconexóes multidirecionais que se estabelece entre as demais dimensóes, parece ser muito mais apropriado em termos de sustentabilidade. Portanto, assumimos que uma situação de vulnerabilidade é dependente e determinada pela forma como se dá a relação e as ligaçóes entre os ativos e as opçóes/restriçóes na escolha de oportunidades que as pessoas possuem, que na prática podem ou não responder a uma situação de risco ou mudança.

Assim, a singularidade deste momento histórico reside na possibilidade e responsabilidade do controle da vida sobre a Terra. Os riscos e as ameaças em questão são necessariamente contingentes das decisóes humanas, incluindo a possibilidade sem precedentes de autodestruição por um lado ou a radical autotransformação por outro.

\section{BIBLIOGRAFIA}

ADGER, W. Neil. (2000), "Social and ecological resilience: Are they related?". Progress in $\mathrm{Hu}$ man Geography, 24 (3): 347-364. . (2006), "Vulnerability". Global Environmental Change, 16 (3): 268-281.

ADGER, W. Neil \& KELLY, P. Mick. (1999), "Social vulnerability to climate change and the architecture of entitlements". Mitigation and Adaptation Strategies for Global Change, (4): 253-266.

ADGER, W. Neil et al. (2009), "Are there social limits to adaptation to climate change?". Climatic Change, 93 (3-4): 335-354.

ALEXANDER, Lisa et al. (2013), Working Group I Contribution to the IPCC Fifth Assessment Report Climate Change 2013: The Physical Science - Basis Summary for Policymakers. Cambridge, Cambridge University Press.

AMBRIZZI, Tércio et al. (2013), "Contribuição do Grupo de Trabalho 1 ao Primeiro Relatório de Avaliação Nacional do Painel Brasileiro de Mudanças Climáticas. Sumário Executivo GT1”. Rio de Janeiro, Painel Brasileiro de Mudanças Climáticas.
ANA - AGÊNCIA NACIONAL DE ÁGUAS. (2010), Atlas Brasil-Abastecimento urbano de água. Panorama Nacional. Brasília, ANA-Engecorps/Cobrape, vol. 1.

ASSAD, Eduardo Delgado et al. (2013), "Impactos, vulnerabilidades e adaptação - Contribuição do Grupo de Trabalho 2 ao Primeiro Relatório de Avaliação Nacional do Painel Brasileiro de Mudanças Climáticas. Sumário Executivo do GT2". Rio de Janeiro, Painel Brasileiro de Mudanças Climáticas (PBMC).

BAI, Zhanguo et al. (2008), "Proxy global assessment of land degradation". Soil Use and Management, 24 (3): 223-234.

BEBBINGTON, Anthony. (1999), "Capitals and capabilities: a framework for analyzing peasant viability, rural livelihoods and poverty". World development, 27 (12): 2021-2044.

BECK, Ulrich. (2009), "World risk society", in J. K. B. Olsen, S. A. Pedersen e V. F. Hendricks (eds.), A Companion to the philosophy of technology, West Sussex, Reino Unido, Wiley-Blackwell.

. (2010), "Climate for change, or how to create a green modernity?". Theory, Culture \& Society, 27 (2-3): 254-266.

BEDDINGTON, John R et al. (2012), "Agriculture. What next for agriculture after Durban?”. Science, 335 (6066): 289-290.

BEG, Noreen et al. (2002), "Linkages between climate change and sustainable development". Climate Policy, 2: 129-144.

BIERMANN, Frank et al. (2012), "Navigating the anthropocene: improving earth system governance". Science, 335 (6074): 1306-1307.

BROWN, Katrina. (2011), "Sustainable adaptation: an oxymoron?". Climate and Development, 3 (1): 21-31.

CEDEPLAR-UFMG - Centro de Desenvolvimento e Planejamento Regional - Universidade Federal de Minas Gerais \& FIOCRUZ - Fundação Oswaldo Cruz. (2009), Mudanças climáticas, migraçôes e saúde: cenários para o Nordeste Brasileiro 2000-2050. Belo Horizonte, UFMG.

CMMAD - Comissão Mundial sobre Meio Ambiente e Desenvolvimento/ONU - Organização das Nações Unidas. (1991), Nosso futuro comum. 2. ed., Rio de Janeiro, Editora da FGV. 
COSTANZA, Robert et al. (2007), "Sustainability or collapse: what can we learn from integrating the history of humans and the rest of nature?". Ambio, 36 (7): 522-527.

DESSAI, Suraje et al. (2009), "Climate prediction: a limit to adaptation?”, in W. N. Adger, I. Lorenzoni e K. O'Brien (eds.), Adapting to climate change: thresholds, values, governancem Cambridge, Cambridge University Press.

ELLIS, Frank. (1998), "Household strategies and rural livelihood diversification". Journal of Development Studies, 35 (1): 1-38.

. (2000), Rural livelihoods and diversity in developing countries. Nova York, Oxford University Press.

EMBRAPA - Empresa Brasileira de Pesquisa Agropecuária \& UNICAMP - Universidade Estadula de Campinas. (2008), Aquecimento global e a nova geografia da produçáo agrícola no Brasil. Brasília/Campinas, Embrapa/Unicamp.

FAO - Food and Agriculture Organization of the United Nations; IFAD - International Fund for Agricultural Development \& WFP World Food Programme. (2013), The state of food insecurity in the world 2013: the multiple dimensions of food security 2013. Roma, Food and Agriculture Organization of the United Nations.

FEW, Roger. (2003), "Flooding, vulnerability and coping strategies: local responses to a global threat'. Progress in Development Studies, 3 (1): 43-58.

FRANKE, Carlos Roberto et al. (2002), "Impact of the El Niño/Southern Oscillation on visceral leishmaniasis, Brazil”. Emerging Infectious Diseases, 8 (9): 914-917.

GLECKLER, Peter J. et al. (2012), "Human-induced global ocean warming on multidecadal timescales". Nature Climate Change, 2 (6): 1-6.

GUPTA, Joyeeta. (2013), "Global water governance", in Rober Falkner (ed.), The handbook of global climate and environment policy, West Sussex, UK, Wiley-Blackwell.

HOGAN, Daniel Joseph. (2005), "Mobilidade populacional, sustentabilidade ambiental e vulnerabilidade social". Revista Brasileira de Estudos de População População, 22 (2): 323-338.
HULME, Mike. (2011), "Reducing the future to climate: a story of climate determinism and reductionism”. Osiris, 26 (1): 245-266.

KELLY, P. Mick \& ADGER, W. Neil. (2000), "Theory and practice in assessing vulnerability to climate change and facilitating adaptation". Climatic Change, 47: 325-352.

KIRKBY, John et al. (2001), "Introduction: Rethinking environment and development in Africa and Asia”. Land Degradation \& Development, 12 (3): 195-203.

KOSAKA, Yu \& XIE, Shang-Ping. (2013), "Recent global-warming hiatus tied to equatorial Pacific surface cooling". Nature, 501 (7467): 403-407.

LINDOSO, Diego Pereira et al. (2005), “Agricultura familiar e mudanças climáticas: avaliando a vulnerabilidade à seca no semiárido nordestino", in Ronaldo Seroa da Motta et al. (org.), Mudança do clima no Brasil: aspectos econômicos, sociais e regulatórios, Brasília, Ipea.

LOBELL, David B. et al. (2011), "Nonlinear heat effects on African maize as evidenced by historical yield trials". Nature Climate Change, 1 (1): 42-45.

LORENZONI, Irene et al. (2007), "Barriers perceived to engaging with climate change among the UK public and their policy implications". Global Environmental Change, 17 (3-4): 445459.

MAMUN, Abdullah-Al. (2010), "Understanding the value of local ecological knowledge and practices for habitat restoration in human-altered floodplain systems: a case from Bangladesh”. Environmental Management, 45 (5): 922-938.

MARENGO, José A. (2007). Mudanças climáticas globais e efeitos sobre a biodiversidade: caracterização do clima no século $X X$ e cenários climáticos no Brasil e na América do Sul para o século XXI. 2. ed. Brasília, Ministério do Meio Ambiente.

MCGRANAHAN, Gordon et al. (2007), "The rising tide: assessing the risks of climate change and human settlements in low elevation coastal zones". Environment and Urbanization, 19 (1): 17-37. 
MENDONÇA, Mário Jorge Cardoso de \& MOTTA, Ronaldo Seroa da. (2007), "Saúde e saneamento no Brasil”. Planejamento e Políticas Públicas, 30: 15-30.

MORAES, Wanderson Bucker et al. (2011), "Potenciais impactos das mudanças climáticas globais sobre a agricultura”. Revista Trópica - Ciências Agrárias e Biológicas, 5 (2): 3-14.

MORAND, Pierre et al. (2012), "Vulnerability and adaptation of African rural populations to hydro-climate change: experience from fishing communities in the Inner Niger Delta (Mali)". Climatic Change, 115 (3-4): 463-483.

MORTON, John F. (2007), "The impact of climate change on smallholder and subsistence agriculture". Proceedings of the National Academy of Sciences of the United States of America, 104 (50): 19680-19685.

MWANG'OMBE, Agnes Wakesho et al. (2011), "Livelihoods under climate variability and change: an analysis of the adaptive capacity of rural poor to water scarcity in Kenya's drylands". Journal of Environmental Science and Technology, 4 (4): 403-410.

O’BRIEN, Karen et al. (2007), "Why different interpretations of vulnerability matter in climate change discourses". Climate Policy, 7 (1): 73-88.

REILLY, John et al. (2001), "Climate change. Uncertainty and climate change assessments". Science, 293 (5529): 430-433.

RICKETTS, Taylor H. et al. (2004), "Economic value of tropical forest to coffee production". Proceedings of the National Academy of Sciences of the United States of America, 101 (34): 12579-12582.

ROCKSTRÖM, Johan et al. (2009), "Planetary boundaries: exploring the safe operating space for humanity". Ecology and Society, 14 (2). Disponível em: <http://www.ecologyandsociety.org/vol14/iss2/art32/>. Acesso em: $12 \mathrm{fev}$. 2016.

SCHNEIDER, Stephen H. (2002a), "Can we estimate the likelihood of climatic changes at 2100?”. Climatic Change, 52 (4): 441-451.

___ (2002B), "Global warming: neglecting the complexities”. Scientific American, 286 (1): $62-5$.
SCOONES, Ian. (2009), "Livelihoods perspectives and rural development". Journal of Peasant Studies, 36 (1): 171-196.

___ (2015), Sustainable Livelihoods and Rural Development. Rugby, Warwickshire, UK, Practical Action Publishing.

SEN, Amartya. (2001), Desigualdade reexaminada. Rio de Janeiro, Record.

SERRAO-NEUMANN, Silvia et al. (2013), "Climate change adaptation: is there a role for intervention research?". Futures, 53: 86-97.

SMIT, Barry \& WANDEL, Johanna. (2006), "Adaptation, adaptive capacity and vulnerability”. Global Environmental Change, 16 (3): 282-292.

SMITH, Pete et al. (2008), "Greenhouse gas mitigation in agriculture". Philosophical Transactions of the Royal Society of London. Series B, Biological Sciences, 363 (1492): 789-813.

STOTT, Peter A. \& KETTLEBOROUGH, James A. (2002), "Origins and estimates of uncertainty in predictions of twenty-first century temperature rise". Nature, 416 (6882): 723-726.

THORNTON, Philip K. (2012), Recalibrating food production in the developing world: global warming will change more than just the climate. Copenhagem, CGIAR Research Program on Climate Change.

TURNER II, Billie L. et al. (2003), "A framework for vulnerability analysis in sustainability science". Proceedings of the National Academy of Sciences of the United States of America, 100 (14): 8074-8079.

UNCCD - United Nations Convention to Combat Desertification. (2011), Desertification: a visual synthesis. Bonn, Germany, UNCCD.

UNESCO - United Nations Educational, Scientific and Cultural Organization. (2010), Gender equality: The missing link? Rethinking the internationally agreed development goals beyond 2015. Paris, Unesco.

VERMEULEN, Sonja J. et al. (2012), "Climate change and food systems". Annual Review of Environment and Resources, 37 (1): 195-222.

VIOLA, Eduardo. (2002), "O regime internacional de mudança climática e o Brasil”. RBCS - 
Revista Brasileira de Ciências Sociais, 17 (50): 25-46.

VÖRÖSMARTY, Charles J. et al. (2010), "Global threats to human water security and river biodiversity". Nature, 467 (7315): 555-561.

WISNER, Ben et al. (2004), At risk: natural hazards, people's vulnerability, and disasters. 2. ed. Nova York, Routledge. 


\section{VULNERABILIDADE SOCIAL ÀS MUDANÇAS CLIMÁTICAS EM CONTEXTOS RURAIS}

\author{
Heitor Marcos Kirsch e Sergio \\ Schneider
}

Palavras-chave: Mudança climática; Vulnerabilidade; Capacidade adaptativa.

Este trabalho avaliou uma série de estudos empíricos produzidos em áreas rurais que examinam e relatam os principais aspectos associados às respostas que as pessoas mobilizam no sentido de garantir a subsistência familiar diante dos efeitos adversos das mudanças climáticas. $\mathrm{O}$ objetivo é demonstrar que persiste uma imprecisão na literatura no tocante às principais noçốes que são operadas nessas análises. Imprecisão que acarreta distorçóes na avaliação dos impactos dos sistemas socioambientais afetados pela variação ou transformação dos ciclos naturais. Alternativas mais promissoras nesse sentido são as que incorporam a noção de cadeias causais, em que o acesso ou restrição ao conjunto de ativos é compreendido como determinante na construção da capacidade adaptativa e nas estratégias de enfrentamento das populaçóes, sobretudo daquelas que vivem em ambientes rurais. A vulnerabilidade é compreendida como uma condiçáo social e situacional, em que conjuntos de fatores endógenos e/ou exógenos, em múltiplas escalas e dimensóes, influenciam-se mutuamente.

\section{SOCIAL VULNERABILITY TO CLIMATE CHANGE IN RURAL CONTEXTS}

\author{
Heitor Marcos Kirsch and Sergio \\ Schneider
}

Keywords: Climate Change; Vulnerability; Adaptive Capacity

This article evaluates a series of empirical studies on rural areas that examine and report the main aspects associated with the answers people mobilize in order to ensure family subsistence in face of the adverse effects of climate change. The objective is to demonstrate that an inaccuracy persists in the concerned literature in what regards to the major notions in operation in those analyzes. Such characteristic causes distortions in the assessment of the environmental impacts on the systems affected by the change or transformation of natural cycles. More promising alternatives in this regard are those which incorporate the notion of causal chains, where the access or its restriction to the set of assets is understood as crucial in the construction of adaptive capacity and coping strategies of the population, especially people living in rural environments. Vulnerability is understood as a social and situational condition in which sets of endogenous and/or exogenous factors, at multiple scales and dimensions, influence each other.

\section{LA VULNERABILITÉ SOCIALE AU CHANGEMENT CLIMATIQUE EN MILIEU RURAL}

\author{
Heitor Marcos Kirsch et Sergio \\ Schneider
}

Mots-clés: Changements climatiques; Vulnérabilité; Capacité d'adaptation.

Cette travail a évalué toute une série d'études empiriques produites en milieu rural qui examinent et retracent les principaux aspects liés aux réponses que les personnes indiquent pour assurer la subsistance familiale face aux effets nuisibles des changements climatiques. L'objectif est de démontrer qu'une imprécision persiste dans la littérature concernant les principaux concepts qui sont exploités dans ces analyses. La présence de cette caractéristique entraîne des distorsions dans l'évaluation des impacts des systèmes sociaux-environnementaux affectés par la variation ou par la transformation des cycles naturels. Les alternatives les plus prometteuses à cet égard sont celles qui intègrent la notion de chaînes de causalité, où l'accès (ou la restriction) à l'ensemble des actifs est comprise comme cruciale à la construction de capacités d'adaptation et des stratégies de résistance des populations, surtout de celles qui vivent en milieu rural. La vulnérabilité est comprise comme une condition sociale et de situation dans laquelle des ensembles de facteurs endogènes et / ou exogènes à échelles et dimensions multiples s'influencent mutuellement. 